\title{
FURTHER EXPERIMENTS IN PHONETIC SYMBOLISM
}

\author{
By Stanley S. Newman, University of Chicago
}

Many persons believe that phonetic elements, apart from their function in a particular linguistic context, carry with them certain symbolic connotations. ${ }^{1}$ The vowels $o$ and $u$, for instance, are said to be heavier, gloomier, more ponderous than $i$ and $e$.

Although one might extend indefinitely this type of phonetic interpretation, one cannot escape the conviction that normal individuals would tend to disagree considerably in the specific symbolism associated with any vowel or consonant. However true this suspicion of individual difference may be, it does not follow that phonetic sounds in themselves have no consistent symbolic relation outside of their linguistic associations. The two problems are generally confused, and both are branded with the stigma of being unreliably intuitive. The point is stressed because I found, from speaking to a number of the students acting as subjects in this investigation, that their assurance on this matter was at striking variance with their reactions in the experiments. They seemed to feel that the process disclosing the symbolic implications of phonetic elements was in some way a highly variable and arbitrary intuitive association. And this point of view, I am sure, reflects common opinion.

But the practical use of this extra-linguistic function of phonetic sounds is familiar enough in literature. The contemporary minor poet, for example, uses great ingenuity in employing this device to gain his effects.

This paper is an attempt to study the patterning of phonetic symbolisms on a non-linguistic plane. For this purpose a schedule was devised employing paired nonsense words. The pairs were so arranged that they would be similar in every respect but for the two vowels or consonants that were to be contrasted, e.g. glupa: glopa. The arbitrary meaning "horse"

* Accepted for publication June 1, 1931. This study was sponsored by the Social Science Research Committee at the University of Chicago.

$\rightarrow$ Edward Sapir, A study in phonetic symbolism, J. Exper. Psychol., 12, 1929, 225-239. I am deeply indebted to Professor Sapir for his assistance in this study. The data of Experiment I were collected by him and handed over to me for inclusion in this paper; a preliminary analysis of some of that material will be found on pages $229-236$ of his article. 
was applied to this pair, and the subjects were asked to choose whether the first word of the pair signified to them the larger or the smaller horse. The subjects were given a sheet with consecutive pairs of numbers; after the investigator pronounced the word pair and gave the arbitrary meaning, the subjects recorded their vote by checking the appropriate number.

TABLE I

Key to Phonetic Symbols

Experiment I

$\begin{array}{llll}i & \text { as in French fini } \\ e & \text { " } & \text { " été } \\ \epsilon & \text { " } & \text { English met } \\ \ddot{a} & \text { " } & \text { " } & \text { hat } \\ a & \text { " } & \text { German Mann } \\ u & \text { " } & \text { English put } \\ o & \text { " } & \text { " } & \text { French tôt } \\ \nu & \text { " } & \text { " } & \text { note }\end{array}$

Experiment II

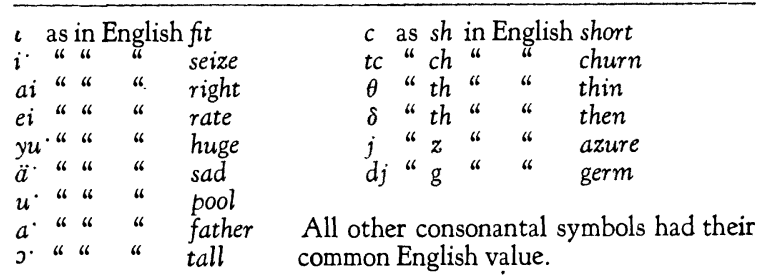

The statistical method employed in treating the data is a psychophysical method arranged by L. L. Thurstone. ${ }^{2}$ The procedure consists essentially of reducing the experimental proportions to sigma scores on a normal curve of distribution. The mean sigma separations between adjacent stimuli are computed, and a final scale is then made from the accumulated steps of the individual stimuli.

Experiment $I$. One hundred word-pairs were used. Each phonetic contrast, however, was presented more than once throughout the hundred pairs; so that the proportions (See Table II) are average percentages of 2 to 5 responses for the given contrast.

The symbolism, on the basis of which the Ss were to make their choice, was that of large versus small.

A variable was introduced in the form of concept classes; the arbitrary meanings of the first 40 pairs were nouns (large versus small objects), the next 10 pairs were verbal subjects (adult versus child activity), the next 10 were adjectives (qualities as applied to large versus small objects), etc. But a comparison of the proportions on the basis of these conceptual categories showed that the variable had no apparent effect on the responses.

The major purpose of this experiment, then, was to discover whether

${ }^{2}$ For a more complete exposition of method see L. L. Thurstone, An experimental study of nationality preferences, J. Gen. Psychol., 1, 1928, 405-425. The reader will find a detailed analysis of the logic underlying this procedure in other articles by the same author. Professor Thurstone has generously given personal advice on many points of statistical method involved in this paper. 
individuals tended to pattern phonetic sounds on the basis of size symbolism. Another purpose was to find whether age differences affected the patterning. The $606 \mathrm{Ss}^{3}$ taking part in the experiment were divided into three age groups:

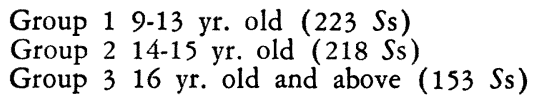

The consonant pairs were not of a sufficient number to permit the calculation of a scale, but will be used in Experiment II.

The tabulated results may be interpreted as follows. In Group 1, 32.2\% of the $S \mathrm{~s}$ voted that $i$ was larger than $e$ (Proportion $i>e=0.322$, Table

TABLE II

\begin{tabular}{|c|c|c|c|c|c|c|c|c|c|}
\hline & & & & MENT & PROPOR & & & & \\
\hline & & $i$ & $e$ & $\epsilon$ & $\ddot{a}$ & $a$ & $u$ & 0 & 0 \\
\hline & $i$. & & .678 & .757 & .812 & .802 & $\cdot 77^{2}$ & & \\
\hline & $e$ & .322 & & .564 & & .742 & & .732 & \\
\hline & $\epsilon$ & .243 & .436 & & .713 & .808 & & & .782 \\
\hline & $\ddot{a}$ & .188 & & .287 & & .576 & .637 & .660 & .717 \\
\hline Group I & $a$ & .198 & .258 & .192 & .424 & & .446 & .600 & .656 \\
\hline & $u$ & .228 & & & .363 & .554 & & .666 & .595 \\
\hline & 0 & & .268 & & .340 & .400 & .334 & & .497 \\
\hline & & & & .218 & .283 & $\cdot 344$ & .405 & .503 & \\
\hline & $i$ & & .705 & .774 & .801 & .828 & .871 & & \\
\hline & $e$ & .295 & & .592 & & .705 & & $.76 \mathrm{I}$ & \\
\hline & $\epsilon$ & .226 & $\cdot 408$ & & .718 & .746 & & & .847 \\
\hline & $\ddot{a}$ & . 199 & & .282 & & .579 & .591 & $.66 \mathrm{I}$ & .659 \\
\hline Group 2 & $a$ & .172 & .295 & .254 & .421 & & .486 & .598 & .642 \\
\hline & $u$ & .129 & & & .409 & .514 & & .656 & .595 \\
\hline & $\begin{array}{l}0 \\
3\end{array}$ & & .239 & & .339 & .402 & $\cdot 344$ & & .450 \\
\hline & 0 & & & .153 & $\cdot 34 \mathrm{I}$ & .358 & .405 & .550 & \\
\hline & $i$ & & .708 & .796 & .864 & .804 & .870 & & \\
\hline & $e$ & .292 & & .593 & & .692 & & .748 & \\
\hline & $\begin{array}{l}\epsilon \\
\ddot{a}\end{array}$ & .204 & .407 & & $\cdot 742$ & $\cdot 747$ & & & .806 \\
\hline Group 3 & $\begin{array}{l}a \\
a\end{array}$ & $\begin{array}{l}.130 \\
.196\end{array}$ & .308 & $\begin{array}{l}.250 \\
.253\end{array}$ & .423 & .577 & $\begin{array}{l}.559 \\
.501\end{array}$ & 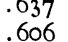 & $\begin{array}{r}.706 \\
567\end{array}$ \\
\hline & $u$ & .130 & & & $.44 \mathrm{I}$ & .499 & & .598 & $\begin{array}{l}.507 \\
.590\end{array}$ \\
\hline & $o$ & & .252 & & .363 & .394 & .402 & & .516 \\
\hline & 0 & & & . I94 & .294 & .433 & .410 & .484 & \\
\hline & $i$ & & .696 & .773 & $.82 \mathrm{I}$ & .812 & .834 & & \\
\hline & $e$ & .304 & 8 & .582 & & .715 & & .747 & \\
\hline & $\begin{array}{l}\epsilon \\
\ddot{a}\end{array}$ & .227 & .418 & & .722 & $\cdot 769$ & & & .812 \\
\hline Average & $a$ & $\begin{array}{r}179 \\
.188\end{array}$ & .285 & $\begin{array}{l}.270 \\
.231\end{array}$ & .423 & .377 & .000 & .054 & $\begin{array}{l}.093 \\
.628\end{array}$ \\
\hline & $u$ & .166 & & & .400 & .525 & & .645 & .594 \\
\hline & $o$ & & .253 & & $\cdot 346$ & .399 & .355 & & .485 \\
\hline & & & & . 188 & .307 & $\cdot 372$ & .406 & .515 & \\
\hline
\end{tabular}

\footnotetext{
${ }^{3}$ Not included in this grouping are twelve schedules received from Chinese students; these will be held until further work is done with phonetic symbolisms among foreign-speaking individuals.
} 




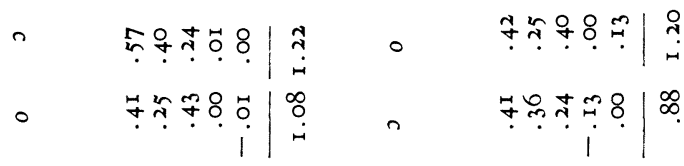

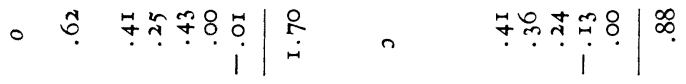

$$
\begin{aligned}
& \text { - }
\end{aligned}
$$

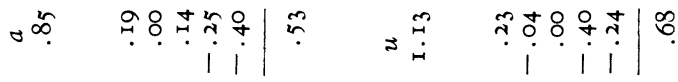

$$
\begin{aligned}
& \text { = }
\end{aligned}
$$

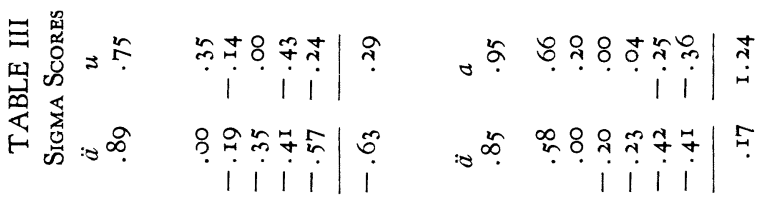

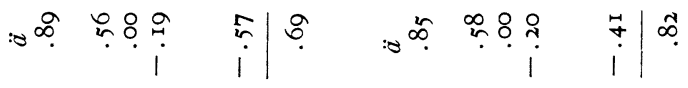

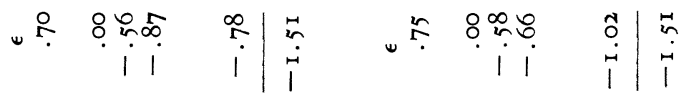

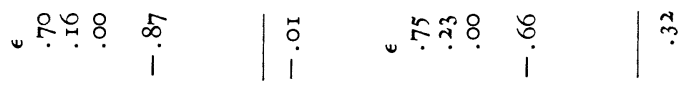

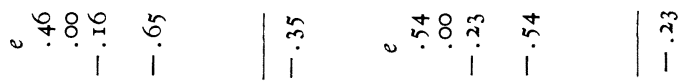

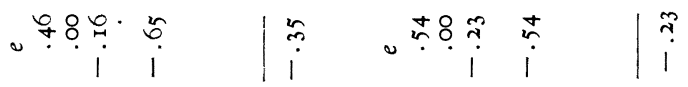

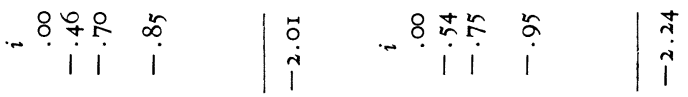

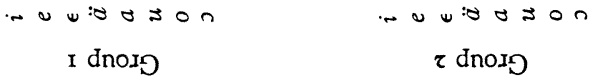




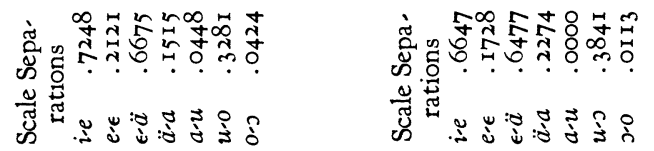

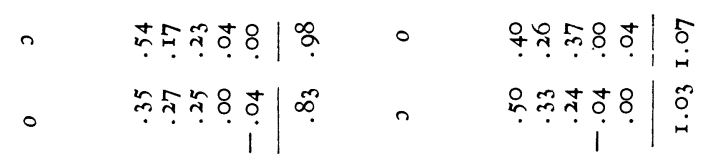

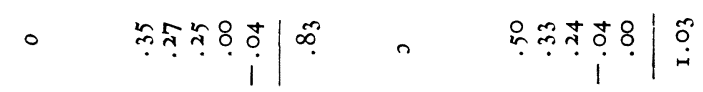

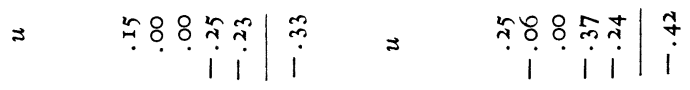

$$
\begin{aligned}
& \text { × }
\end{aligned}
$$

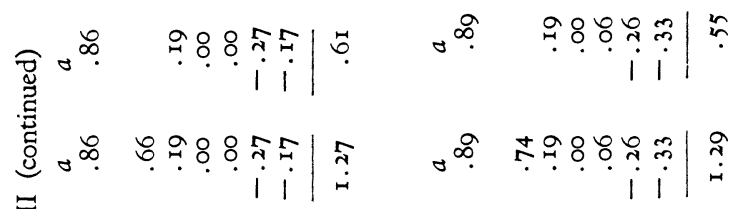

$$
\begin{aligned}
& \text { 岳 } \\
& \text { : } \\
& \text { 舟 }
\end{aligned}
$$

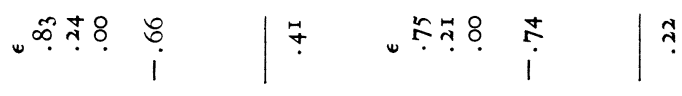

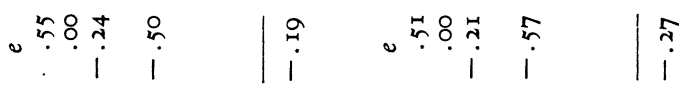

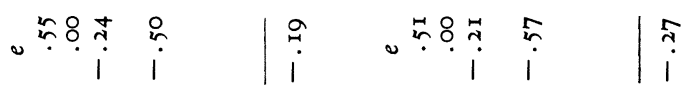

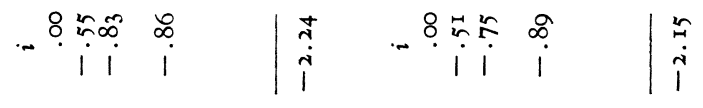

$$
\begin{aligned}
& \text { a nis ason } \\
& \varepsilon \text { dnox } \\
& \text { วถిยาวน }
\end{aligned}
$$


II, top of $i$-column). This proportion corresponds to the sigma score -0.46 (Table III). The scale separation between $i$ and $e$ is the mean difference between the repeated sigma scores of the two stimuli multiplied by $2^{1 / 2}$, the discriminal errors of the stimuli. ${ }^{4}$

$$
\begin{aligned}
\mathrm{S}_{\mathrm{I}}-\mathrm{S}_{2} & =\mathrm{x}_{12}(2)^{1 / 2} \\
& =[(-35 \times 2.01) / 4](2)^{1 / 2} \\
& =\left(1.66^{\prime} 4\right)(2)^{1 / 2} \\
& =.45 \times(2)^{1 / 2} \\
& =.5869
\end{aligned}
$$

The scale values are derived from the accumulated scale separations between adjacent stimuli (Table IV). The position of any vowel on the

TABLE IV

$\mathrm{S}$ :ALE VALUES

$\begin{array}{lrrrrr} & \text { Group I } & \text { Group 2 } & \text { Group 3 } & \text { Av. } & \text { Median* } \\ i & .0000 & .0000 & .0000 & .0000 & .0000 \\ e & .5869 & .7106 & .7248 & .6647 & .7106 \\ \epsilon & .7071 & .9050 & .9369 & .8375 & .9050 \\ \ddot{a} & 1.3293 & 1.5640 & 1.6044 & 1.4852 & 1.5640 \\ a & 1.6027 & 1.7802 & 1.7559 & 1.7126 & 1.7802 \\ u & 1.5461 & 1.8038 & 1.8007 & 1.7126 & 1.8038 \\ o & 1.9256 & 2.2705 & 2.1288 & 2.1080 & 2.1833 \\ \nu & 1.9652 & 2.1800 & 2.1712 & 2.0967 & 2.2229\end{array}$

* The Median Scale Values are determined on the basis of median scale separations.

symbolic scale is a medial point computed from its various positions when contrasted with individual vowels.

It is further possible to determine the range of shifting that each item undergoes: thus, $i$ will take one position on the scale when contrasted with $e$, another when contrasted with $\varepsilon$, etc. The scale separation 0.5869 , or $0.415 \sigma$, between $i$ and $e$ corresponds to the proportion 0.339 for $i$. The difference between the experimental proportion and the calculated proportion $\left(\mathrm{Pe}-\mathrm{PC}_{\mathrm{C}}\right)$ is $-0.017(.322-.339=-.017)$. Such a method of computing discrepancies is, as one may assume, a test of the internal consistency of the responses.

The subjective scales of the three groups reveal the same essential patterning (Fig. 1). The vowel $i$ always occurs relatively far below the succeeding vowel $e$, which is followed rather closely by $\varepsilon$, after which comes $\ddot{a}$ separated by another considerable distance. Slight inconsistencies appear in the allocation of $a$ against $u$ and again in $o$ against 0 ; but these two groups of vowels are close together on each of the three scales, and the inconsistencies, falling well within the average discrepancy area, are further reflected in a comparison of discrepancy ranks.

\footnotetext{
4 Thurstone, op. cit., p. 407.
} 


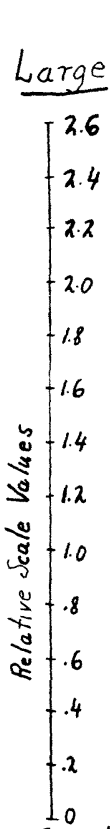

Small
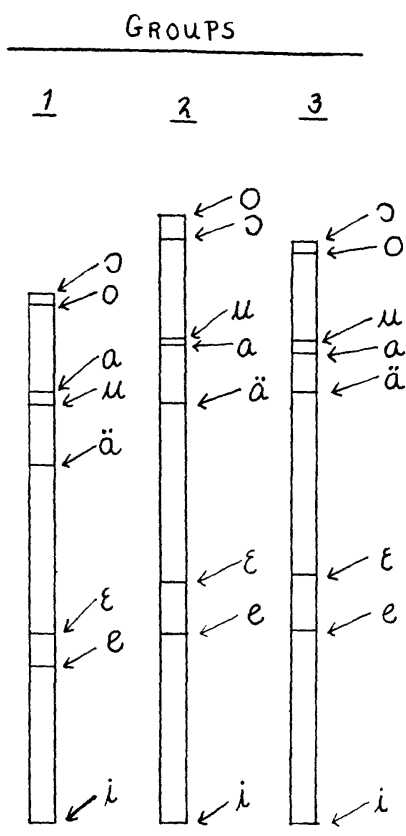

AverAGE

MEDIAN
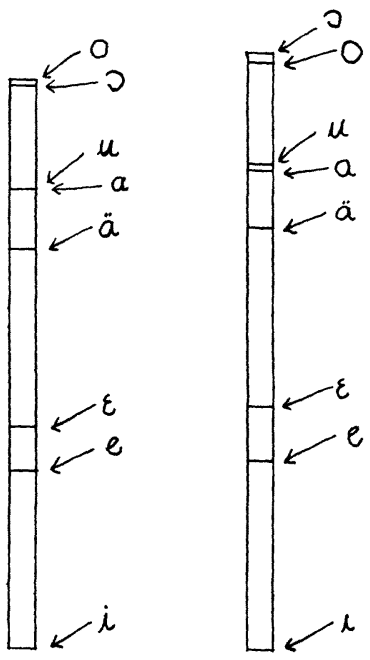

Fig. 1. Symbolic Magnitude Scales

The discrepancies in many ways tell a significant story. An examination of the average discrepancies (Table $\mathrm{V}$ ) indicates that the youngest group shows the greatest degree of inconsistency $(0.041)$, the older group displays less $(0.035)$, and the oldest group has the least $(0.032)$. This is a situation one might expect; and it bears out the fact that the scale separations of Group 1 are the smallest, this group tending to discriminate between the vowels less distinctly than the other groups. But it should be observed that these scale and discrepancy differences between the age-groups are only slight differences in the clarity and stability of discriminal perception, not in fundamental pattern. In other words, the youngest group has substantially the same subjective pattern as the older groups, but it tends to discriminate less sharply and less consistently than they do between the sounds.

A comparison of the individual discrepancies, however, suggests that the use of these to explain the range of instability interprets only a part of the evidence. In the majority of cases the shifting appears to be of the same general trend. A few examples are listed:

Groups

\begin{tabular}{lrrrr} 
& \multicolumn{1}{c}{$\mathrm{I}$} & \multicolumn{1}{c}{. } & \multicolumn{1}{c}{. } & \\
$i>e$ & -.017 & -.013 & -.012 & -.015 \\
$i>\epsilon$ & -.066 & -.035 & -.050 & -.050 \\
$i>a$ & .069 & .068 & .089 & -.075 \\
$e>\epsilon$ & -.030 & -.037 & -.033 & -.033 \\
$e>0$ & .096 & .104 & .092 &. .099 \\
$\epsilon>\ddot{a}$ & -.043 & -.039 & -.060 & -.045 \\
$\ddot{a}>0$ & .003 & .030 & .008 & .016 \\
$a>u$ & .038 & .021 & .012 & .025 \\
$u>0$ & .021 & .010 & .013 & .013
\end{tabular}


These phenomena indicate that the discrepancies point not only to chance fluctuations and inconsistencies but to constant shifts. The reasons behind such constant variability cannot be satisfactorily explained from the details of the available data; but it is significant to note that even the low discrepancy of the average scale

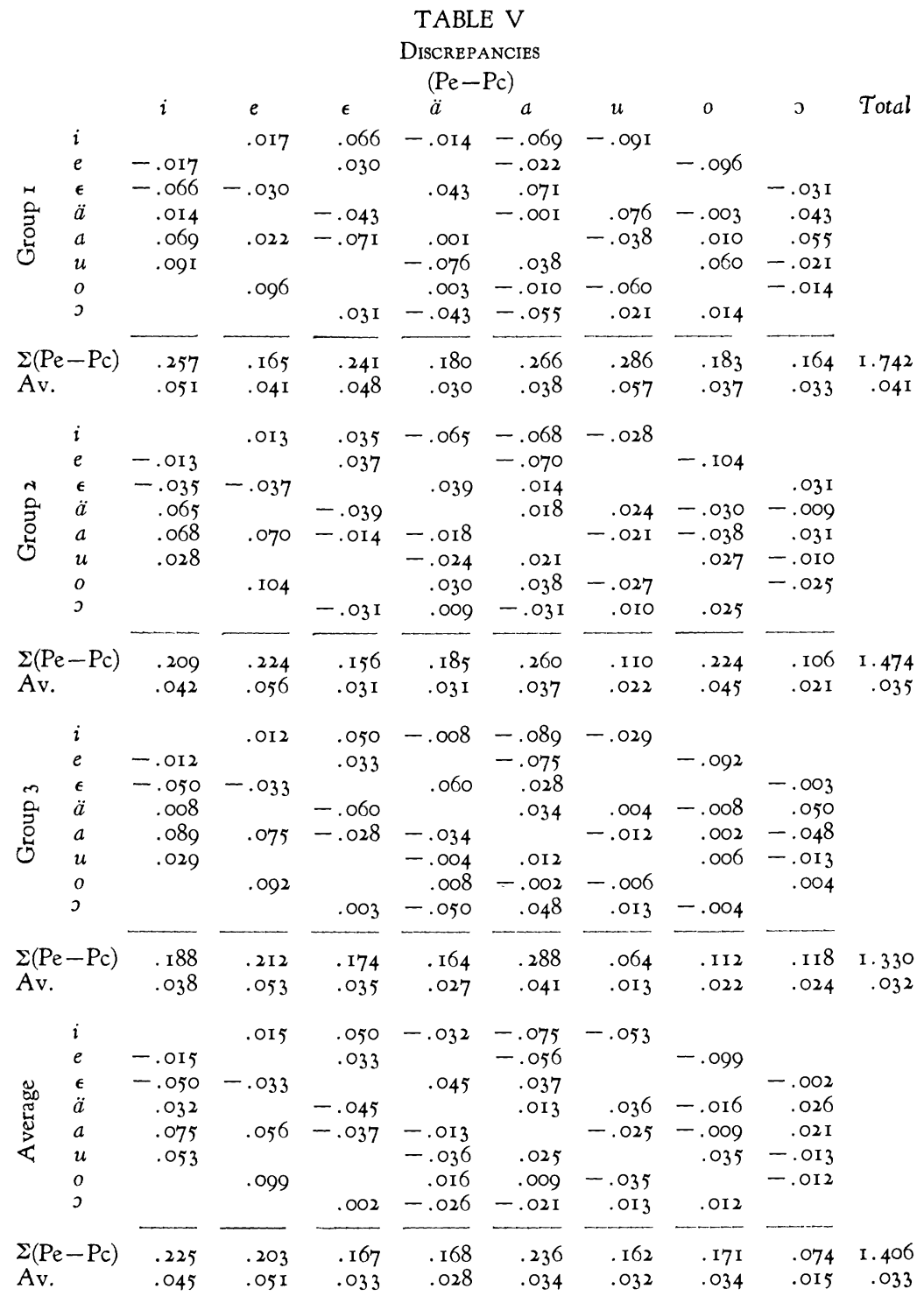


(0.033) is probably much too high if one takes this figure merely as an index of inconsistency. We are evidently dealing with a field of latent symbolism in which the patterning is even more rigid and constant than the discrepancies would lead us to believe.

A consideration of the discrepancies from another point of view helps to allocate the scale-inconsistencies referred to above. The vowel $u$ falls below $a$ on the scale of Group 1, contradicting the alignment of these vowels on the scales of the other two groups; likewise, the vowel 0 , in appearing above 0 on the scale of Group 2, falls out of the pattern set by the other two groups. If the 8 vowels are arranged in rank order of their discrepancy-scores within each group, the $u$ of Group

\begin{tabular}{|c|c|c|c|c|c|}
\hline & & $\begin{array}{r}D \\
\text { Grou }\end{array}$ & $\begin{array}{l}\mathrm{VI} \\
\mathrm{R}_{\mathrm{A}}\end{array}$ & & \\
\hline & I & 2 & 3 & Av. & Median \\
\hline$i$ & 7 & 6 & 6 & 7 & 6 \\
\hline$e$ & 5 & 8 & 8 & 8 & 8 \\
\hline$\epsilon$ & 6 & 4 & 5 & 4 & 5 \\
\hline$\ddot{a}$ & I & 3 & 4 & 2 & 3 \\
\hline$a$ & 4 & 5 & 7 & 5 & 5 \\
\hline$u$ & $8^{*}$ & 2 & I & 3 & 2 \\
\hline 0 & 3 & $7^{*}$ & 2 & 6 & 3 \\
\hline 0 & 2 & I & 3 & I & 2 \\
\hline
\end{tabular}

1 and the $o$ of Group 2 will be found to have a much higher discrepancy rank than these vowels in the other groups. The two starred examples, it will be noted, depart farther from a median discrepancy rating than any of the other examples in the entire set. We may assume, then, that the normal position of $u$ is slightly above $a$ on the subjective scale, and $o$ is slightly below $\partial$; since in each case we are taking as the norm the choice of two groups having a low discrepancy-rank for these vowels as against that of one group having a strikingly high discrepancyrank.

In general, the rationale which underlies the symbolic magnitude-pattern appears to be of a mechanical nature. The front vowels of the symbolic scale follow the order, $i, e, \varepsilon, \ddot{a}, a$. This sequence is similar to a vowelseries following (1). the receding positions of articulation made by the tongue within the mouth, (2) the decreasing frequencies of vocalic resonance as measured acoustically, and (3) the increasing size of the oral cavity used in pronunciation. Thus far the three factors work in unison to present the same picture of a vowel sequence as that found on the symbolic scale. But these factors are at variance in their arrangement of the back vowels. The situation might be schematized as follows:

(1) Kinesthetic factor: articulatory position of tongue (front to back), $i, e, \varepsilon, \ddot{a}, a, \jmath, o, u$. 
(2) Acoustic factor: characteristic high frequency of vocalic resonance (high to low), ${ }^{5} i, e, \varepsilon, \ddot{a}, a$, o, $o, u$.

(3) Kinesthetic or, possibly, visual factor: size of oral cavity (small to large), i, e, $\varepsilon, \ddot{a}, a ; u, o$, o.

The symbolic magnitude-pattern conforms to the first two series in placing the back vowels above the front vowels; but it compensates for this arrangement, as it were, by following the sequence of the third series. But the group-scales are not entirely consistent in their sequence of back vowels, as was pointed out above; furthermore, their arrangement of back vowels leans more heavily on the patterns of factors 1 and 2-the matter of placing the back vowels above the front being a more thoroughgoing spatial discrimination than the matter of sequence. For these reasons we may assume that the size of the oral cavity is a less potent factor in judgments of magnitude-symbolism than the accompanying factors of articulatory position and acoustic resonance.

Experiment II. A related experiment was conducted to determine the bearing of unlike symbolisms on the subjective patterns of phonetic sounds. The symbolisms chosen were (A) large versus small, and (B) dark versus bright.

The experimental and statistical procedure was essentially the same as that of Experiment I. A schedule of 113 word-pairs was drawn up, contrasting 9 vowels and 15 consonants. Each contrasting pair of vowels and of consonants was presented only once, in distinction to the previous experiment. Another difference of procedure was that the phonetic elements in this experiment were restricted to English sounds. The purpose of this restriction was to permit, later on, a comparison of the distribution of sounds on a symbolic scale with their distribution in meaningful English words. The Ss were asked to choose the symbolically 'larger' word of each pair during the first half of the experiment; the same pairs were then given in random order and the Ss were asked to choose the 'darker' word.

\begin{tabular}{|c|c|c|c|}
\hline \multicolumn{4}{|c|}{ TABLE VII } \\
\hline Contrasts & Position & Accent & Syl. Structure \\
\hline sú tha: sitha & Ist syl. & acc. & « syl. word \\
\hline 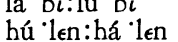 & “ $"$ & $\begin{array}{l}\text { unacc. } \\
\text { acc. }\end{array}$ & “ " " final cons. \\
\hline péiksa:pú ksa & “ $"$ & “. & “ " “ cons. doublet \\
\hline $\mathrm{ka}^{\prime}$ ú $:$ :kalái & 2nd syl. & “ & " « " \\
\hline $\begin{array}{l}\text { dágu' :dágo }{ }^{\circ} \\
\text { dzu }{ }^{\circ} \text { : } \text { dzyu }^{\circ} \mathrm{c}\end{array}$ & " « & unacc. & " " " " \\
\hline
\end{tabular}

${ }^{5}$ Richard Paget, Human Speech, 1930, 86-93, 315-317. No adequate acoustic analysis has been made of the entire vocalic gamut for one voice. This acoustic scale has been assembled from the frequency-data of several voices; it is only an approximation, valid enough as an index of relative position, although it cannot claim any absolute numerical validity. 
Because the total experiment contained 226 word-pairs, it was decided to vary the phonetic structure of the words in order to prevent, as far as possible, a deadening of the Ss' attention. The contrasted sounds were varied as to position in the word, accent, and syllabic structure. In the vowel-pairs, for instance, the contrasted elements might take any of the forms given in Table VII. But these variations were introduced consistently into the sounds, so that, if they should prove to be conditions affecting the responses, their total effect on the symbolic scale would be constant and uniform, although their individual values could still be computed.

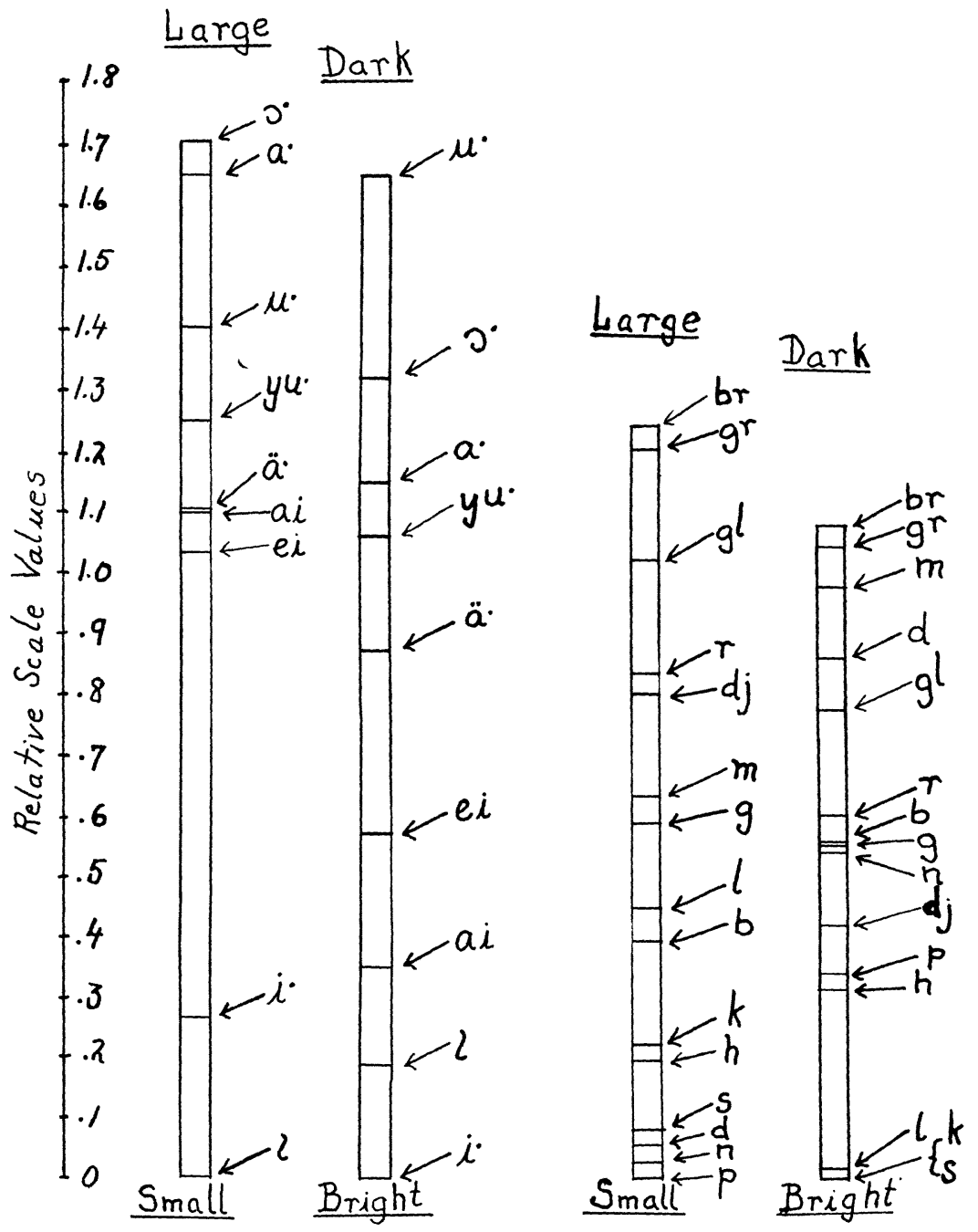

Fig. 2. Symbolic Scales 


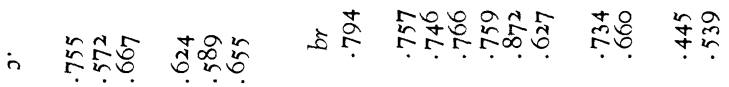

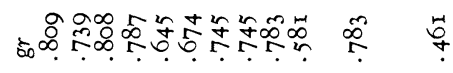



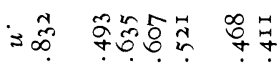

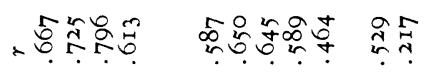

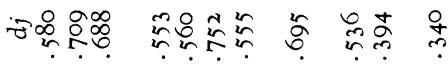

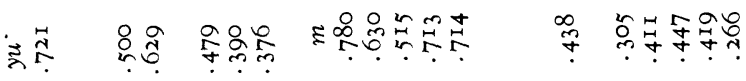

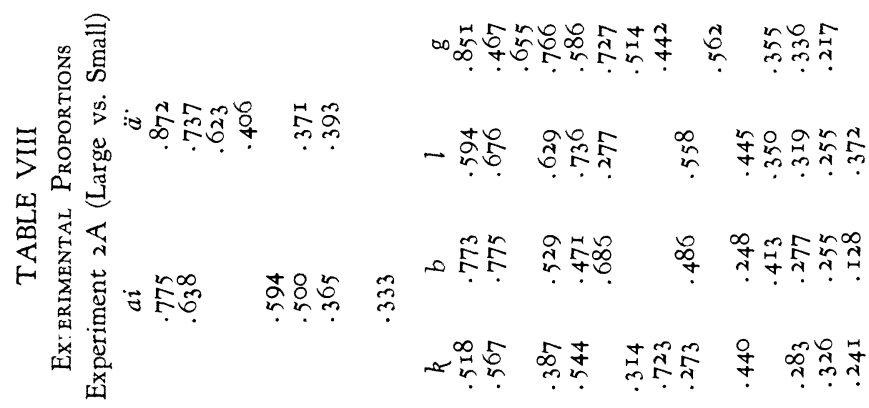

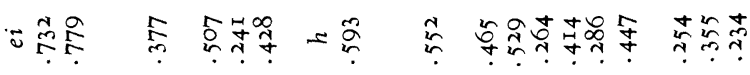

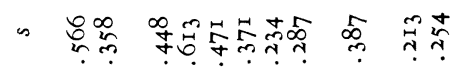

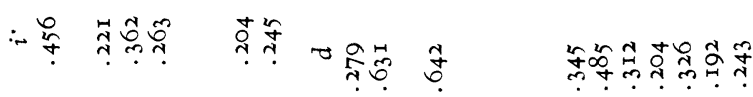

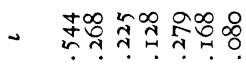

×

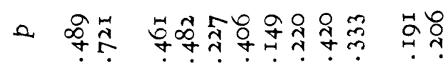

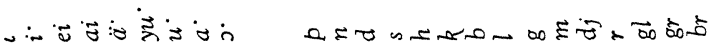




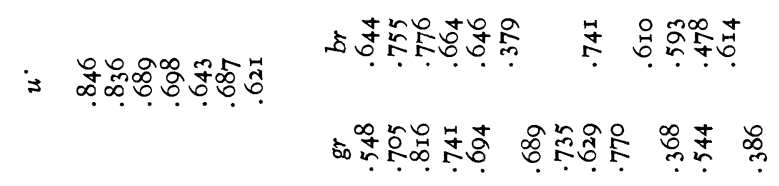

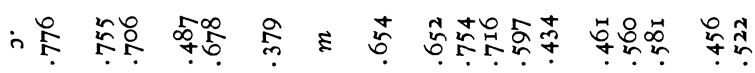

-

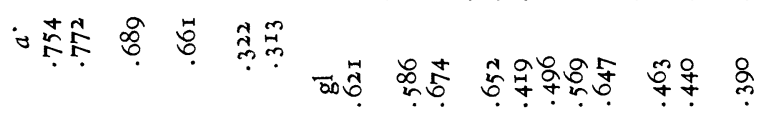

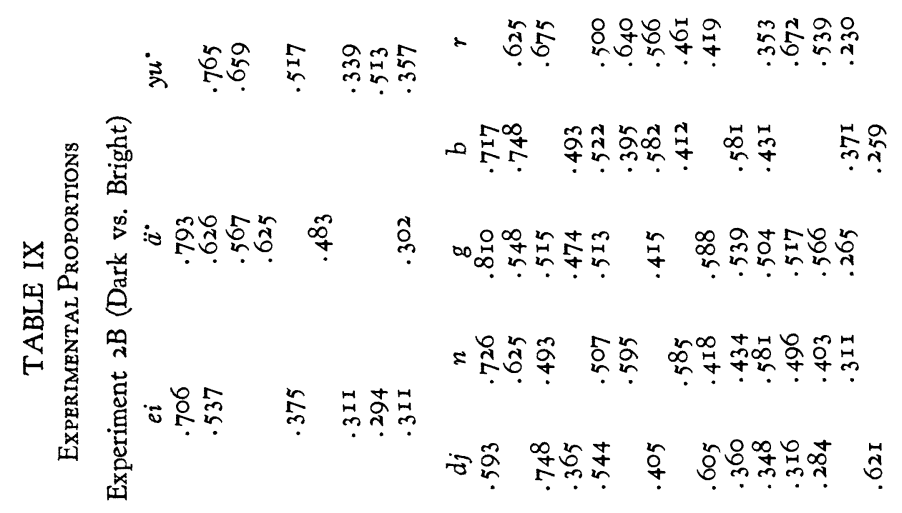

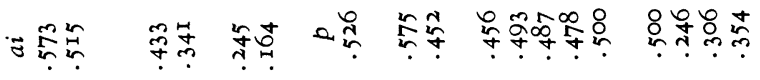

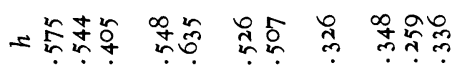

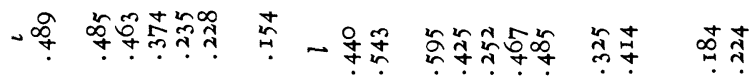

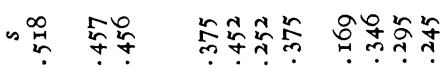

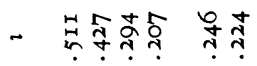

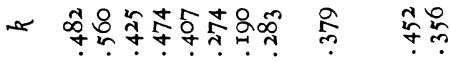

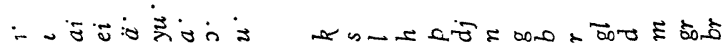


TABLE X

An Example of Scale Calculation

Vowels of Experiment 2A (Large vs. Small)

Sigma Scores

Original Calculation

\begin{tabular}{|c|c|c|c|c|c|c|c|c|}
\hline & $\iota$ & $i$ & $i^{\circ}$ & $e i$ & $e i$ & $\dddot{a}$ & $\ddot{a}^{\cdot}$ & $a i$ \\
\hline ‘ & .00 & -.II & -.II & .62 & .62 & I. I 4 & I. I 4 & .76 \\
\hline$i^{\circ}$ & . II & .00 & .00 & .77 & .77 & .63 & .63 & .35 \\
\hline$e i$ & -.62 & -.77 & -.77 & .00 & .00 & $.3 \mathrm{I}$ & & \\
\hline$\dddot{a}^{\circ}$ & $-\mathrm{I} . \mathrm{I} 4$ & -.63 & -.63 & $-.3 \mathrm{I}$ & $-.3 \mathrm{I}$ & .00 & .00 & .24 \\
\hline$a i$ & -.76 & -.35 & & & & & -.24 & .00 \\
\hline$y u{ }^{\circ}$ & & & & & & & -.33 & .00 \\
\hline . & & & & & .02 & -.27 & -.27 & -.35 \\
\hline $\begin{array}{l}a^{\circ} \\
j^{\circ}\end{array}$ & $-\mathrm{I} .4 \mathrm{I}$ & -.83 & $\begin{array}{l}-83 \\
-.60\end{array}$ & $\begin{array}{l}-.70 \\
-.18\end{array}$ & & & & \\
\hline & -3.82 & -2.69 & -3.03 & .20 & 10 & ${ }^{2}{ }_{\mathrm{I}}$ & 03 & I. 00 \\
\hline & $a i$ & $\nu u^{\circ}$ & $v u^{\circ}$ & $u^{\circ}$ & & $\theta^{\circ}$ & $a^{\circ}$ & \\
\hline$\iota$ & .76 & 50 & yu & .06 & .06 & I. $4 \mathrm{I}$ & $a$ & J \\
\hline$i$ & & (3) & עוני & & & & .83 & .69 \\
\hline$e i$ & & & & & -.02 & .70 & .70 & .18 \\
\hline$\ddot{a}$ & .24 & .33 & .33 & .27 & & & & \\
\hline$a i$ & .00 & .00 & .00 & .35 & & & & \\
\hline$y u^{\circ}$ & .00 & .00 & .00 & .05 & .05 & .28 & .28 & .32 \\
\hline$u$ & -.35 & -.05 & -.05 & .00 & .00 & .08 & .08 & .22 \\
\hline$a^{\circ}$ & & & -.28 & -.08 & -.08 & .00 & .00 & .40 \\
\hline $0^{\circ}$ & -.43 & -.32 & -.32 & -.22 & -.22 & -.40 & -.40 & .00 \\
\hline & .22 & .55 & .27 & I. 33 & .69 & 2.07 & I. 49 & $\mathrm{I} .8 \mathrm{I}$ \\
\hline
\end{tabular}

Supplemented Calculation

\begin{tabular}{|c|c|c|c|c|c|c|c|c|c|}
\hline & $\iota$ & $i^{\circ}$ & $e i$ & $a i$ & $\ddot{a}$ & $y u^{\circ}$ & $u^{\circ}$ & $a^{\circ}$ & $0^{\circ}$ \\
\hline$\iota$ & .00 & -.III & .62 & .76 & I. I 4 & .59 & .96 & $\mathrm{I} .4 \mathrm{I}$ & I. $37^{*}$ \\
\hline$i$ & . II & .00 & .77 & .35 & .63 & $.75^{*}$ & $.90^{*}$ & .83 & .69 \\
\hline$e i$ & -.62 & -.77 & .00 & $.15^{*}$ & $.3 \mathrm{I}$ & $.2 \mathrm{I}^{*}$ & -.02 & .70 & .18 \\
\hline$a i$ & -.76 & -.35 & $-.15^{*}$ & .00 & -.24 & .00 & .35 & $.44^{*}$ & .43 \\
\hline$\ddot{a}$ & -I.I4 & -.63 & -.31 & .24 & .00 & .33 & .27 & $.45^{*}$ & $.50^{*}$ \\
\hline$y u$ & -.59 & $-.75^{*}$ & $-.2 \mathrm{I}^{*}$ & .00 & -.33 & .00 & .05 & .28 & .32 \\
\hline & -.96 & $-.90^{*}$ & .02 & -.35 & -.27 & -.05 & .00 & .08 & .22 \\
\hline$a$ & $-\mathrm{I} .4^{\mathrm{I}}$ & -.83 & -.70 & $-.44^{*}$ & $-.45^{*}$ & -.28 & -.08 & .00 & .40 \\
\hline $0^{\circ}$ & $-1.37^{*}$ & -.69 & -.18 & -.43 & $-.50^{*}$ & -.32 & -.22 & -.40 & .00 \\
\hline & & .03 &.$- I_{4}$ & .28 & 29 & I. 23 & $2.2 \mathrm{I}$ & .79 & . II \\
\hline
\end{tabular}

* Supplemented sigma scores, calculated from the original scale

TABLE XI

ScAle Values

Experiment $2 A$ (Large vs. Small)

$\begin{array}{ll}\iota . & .0000 \\ i & .2687 \\ e i & 1.0370 \\ a i & 1.1029 \\ \ddot{a} . & \mathrm{I} .1045 \\ y u . & \mathrm{I} .252 \mathrm{I} \\ u^{\circ} \cdot & \mathrm{I} .406 \mathrm{I} \\ a^{\circ} & \mathrm{I} .6544 \\ \mathrm{~J} . & \mathrm{I} .7047\end{array}$

$\begin{array}{ll}p & .0000 \\ n & .0254 \\ d & .0555 \\ s & .0800 \\ h & .1960 \\ k & .2243 \\ b & .3950 \\ l & .4497 \\ g & .5901\end{array}$

$\begin{array}{ll}m & .6354 \\ \text { dj } & .8023 \\ r & .8362 \\ g l & 1.0210 \\ g r & 1.2058 \\ b r & 1.2464\end{array}$




\begin{tabular}{|c|c|c|c|c|c|}
\hline & & $\begin{array}{r}\mathrm{Sc} \\
\mathrm{men}\end{array}$ & $\begin{array}{l}\text { XII } \\
\text { LuEs } \\
\text { rk vs. }\end{array}$ & & \\
\hline$i$ & .0000 & $k$ & .0000 & $r$ & .601 \\
\hline$\iota$ & . 1918 & $s$ & .0000 & $g l$ & .778 \\
\hline$a i$ & .3520 & $l$ & $.015 \mathrm{I}$ & $\mathrm{d}$ & .85 \\
\hline$e i$ & .5736 & $h$ & .3159 & $m$ & $.97^{\prime}$ \\
\hline$\ddot{a}^{\circ}$ & .8752 & $p$ & .3395 & $g r$ & $1.04 ?$ \\
\hline$y u^{\circ}$ & 1.0606 & $d j$ & .4197 & $b r$ & 1.081 \\
\hline$a^{\circ}$ & I. 1534 & $n$ & .5413 & & \\
\hline $0^{\circ}$ & I. 3247 & $g$ & .5545 & & \\
\hline$u^{\circ}$ & I. $653 \mathrm{I}$ & $b$ & .5573 & & \\
\hline
\end{tabular}

TABLE XIII

Average Discrepancies

Experiment $2 A$ (Large vs. Small)

$\begin{array}{ll}\imath & .029 \\ i & .059 \\ e i & .061 \\ a i & .032 \\ \ddot{a} \cdot & .041 \\ y u . & .037 \\ u . & .046 \\ a . & .040 \\ \jmath^{\circ} & .049\end{array}$

Av. $\quad .044$

$\begin{array}{ll}i^{\circ} & .021 \\ \imath & .032 \\ a i & .024 \\ e q & .039 \\ \ddot{a} \cdot & .020 \\ y u \cdot & .065 \\ a \cdot & .053 \\ j^{\circ} & .056 \\ u^{\circ} & .034\end{array}$

Av. $\quad .038$

$\begin{array}{ll}p & .079 \\ n & .055 \\ d & .086 \\ s & .064 \\ h & .056 \\ k & .078 \\ b & .079 \\ l & .063 \\ g & .075\end{array}$

$\begin{array}{ll}m & .074 \\ d j & .073 \\ r & .062 \\ g l & .048 \\ g r & .067 \\ b r & .049\end{array}$

Av. $\quad .067$

TABLE XIV

Average Discrepancies

Experiment $2 \mathrm{~B}$ (Dark vs. Bright)

$\begin{array}{ll}k & .080 \\ s & .062 \\ l & .062 \\ h & .046 \\ p & .043 \\ d_{1} & .108 \\ n & .067 \\ g & .072 \\ b & .062\end{array}$

$\begin{array}{ll}r & .089 \\ g l & .051 \\ d & .086 \\ m & .065 \\ g r & .083 \\ b r & .078\end{array}$

Av. $\quad .070$

Experiment $2 \mathrm{~A}$ (large versus small) was taken by $141 \mathrm{Ss}$, undergraduates at the University of Chicago. Five dropped out after completing Experiment 2A, leaving 136 in Experiment 2B (dark versus bright).

A casual examination of the experimental proportions was sufficient to show that the variations referred to above had a decided effect on the responses (Tables VIII and IX). It was necessary then to supplement the original sigma calculation with one which would make use of all the data, in order that each stimulus-position on the scale would be the result of the total conditions. An example of the two types of calculation is given 
in Table X. The final supplemented scale-values are to be found in Tables $\mathrm{XI}$ and XII and Fig. 2.

A comparison of the vowel-constellations of the two symbolic scales clearly shows two different patterns. The magnitude scale of the previous experiment appeared to be based upon three objective factors: articulatory position, acoustic frequency, and size of oral cavity. A point for point comparison of the symbolic scales of Experiment 1 and Experiment $2 \mathrm{~A}$ is not possible, of course, for the vowels are different. But it will be noted that the same general plan is confirmed; the small-to-large symbolism follows the sequence of receding tongue position, decreasing characteristic high frequency, and increasing size of the oral cavity. The present experiment, however, reveals another factor entering into the judgment of size symbolism; i.e. vocalic length. The position of $i$ above $i$ on the present magnitude-scale runs counter to both the articulatory and frequency sequence. The conclusion can hardly be avoided that $i$ is symbolically larger than ! because the length of the former vowel makes it 'sound' larger. The dark-versus-bright symbolism, on the other hand, seems to be patterned exclusively on an articulatory and frequency basis; the factors of vocalic length and size-of-mouth-opening evidently have nothing to do with the symbolic judgment of relative darkness, a situation which is entirely plausible.

Turning to the consonants, we find similar objectively mechanical factors at work to form the subjective scales. In judgments of small to large the sequence of articulatory position is consistently dental, labial, palatal ( $t$, $p, k ; d, b, g ; n, m)$. This symbolic scale further follows the objective sequence of voiceless to voiced $(t, d ; p, b ; k, g ; s, z ; c, j$; etc.). The consonants conform to a series of phonetic sequences with a fairly definite mathematical regularity. The scale separations between some of the consonantal magnitude-values are listed. ${ }^{6}$

Position:

Voicing:

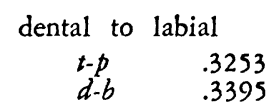

stops

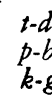

fricatives

$\theta . \delta$

$f-v$
.3808

.3950

.3658

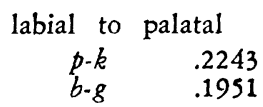

sibilants

$t c-d j \quad .5657$

$c-j \quad .6081$

- The reader should consult the consonantal magnitude-scale of Table XVII, which is more complete in having the consonantal responses of Group 3 (Experiment 1) grafted on the scale of Experiment $2 A$. The consonantal responses of only Group 3 were used because this group corresponded most closely in age and in number of subjects to the group of Experiment $2 \mathrm{~A}$. 
The nasal consonants do not hold a consistent pattern in relation to the stop-consonants of their respective positions; but this apparent inconsistency is carried out in both of the symbolic scales. Although $m$ (labial nasal) is both larger and darker than $b$ (labial voiced stop), $n$ (dental nasal) is both smaller and brighter than $d$ (dental voiced stop).

The bright-to-dark symbolism is likewise objectively phonetic in its consonantal patterning. A voiceless-to-voiced sequence is adhered to, as in the small-to-large symbolism; apparently the voiced consonant, having more acoustic body than a voiceless sound, gives an impression of darkness as well as largeness. The articulatory sequence, on the basis of a bright-todark symbolism, in palatal, labial, dental-an order which is the reverse of that on the magnitude-scale. The palatal consonants, then, are bright but large; the dentals, on the other hand, are dark but small.

The symbolic darkness-scale is not complete enough for a presentation of mathematical relationships between consonants, as was furnished for the magnitude-scale. The pattern of symbolic darkness, as far as one can judge, does not show as thoroughgoing a mathematical regularity between the phonetic relations of consonants as that of symbolic magnitude. Yet when one compares the discrepancies of the consonants with those of the vowels (Tables XIII and XIV), the fact that the former indicate a less reliable index of symbolism makes it all the more surprising that they should be as consistently patterned as they are. Their symbolic ambiguity, in contrast to the vowels, reflects in a sense the embarrassment of acousticians confronted with the problem of making a physical analysis of consonants; if the symbolic judgments of phonetic sounds are based upon their objective properties, as these experiments seem to indicate, a subtlety and variability of objective composition will quite naturally be mirrored in a vagueness of symbolic reference.

The corrections for the variable of phonetic structure were computed from the formula

$$
\mathrm{K}=(\mathrm{Xe}-\mathrm{Xc})(2)^{1 / 2}
$$

$\mathrm{K}=$ the scale distance between the modal stimulus-value and the value of that stimulus under a particular condition of phonetic structure.

$\mathrm{Xe}=$ the experimental sigma-value corresponding to the experimental proportion of a stimulus-pair.

$\mathrm{Xc}=$ the sigma-value of the calculated proportion.

$2^{1 / 2}=$ a constant (the discriminal errors of the stimuli) used in the scale formula (supra p. 58).

An example of the procedure is given: 


$\begin{array}{cccc}\text { Stimulus Contrast } & \mathrm{Xe} & \mathrm{Xc} & \mathrm{Xe}-\mathrm{Xc} \\ \text { b-p } & .6219 & .2793 & .3426 \\ \mathrm{gd} & .3989 & .3780 & .0209^{*} \\ \text { gl-k } & .5740 & .5634 & .0106 \\ \text { gr.m } & .2045 & .4034 & -.1989 \\ r \cdot n & .5978 & .5733 & .0245 \\ l-s & .3292 & .2614 & .0678 \\ \text { dj-h } & .1332 & .4287 & -.2955\end{array}$

All of the consonant pairs in this illustration were given initially, accented, in three-syllable words (báguli-páguli, domali-gomali, glápuni-kápuni, etc.). The median difference between the experimental and the calculated sigma-scores was taken as the normal value for this condition of phonetic structure. This value is starred in the above example. Using formula $\mathrm{K}=(\mathrm{Xe}-\mathrm{Xc})(2)^{1 / 2}$, we may conclude: Init., acc., 3-syl. word $=0.0209$ $(2)^{1 / 2}=0.0296$. This procedure was applied to all pairs presented under the same conditions of phonetic structure. The calculated proportions employed in computing the discrepancies were in each case corrected by the structural condition under which the particular stimulus was given (Discrepancy $=\mathrm{Pe}-\mathrm{Pc}$, in which $\mathrm{Pc}$ is the proportion corresponding to $\mathrm{Xc}$ corrected by the sigma-value of $\mathrm{K}$ ).

In spite of other indeterminate fluctuations disturbing the character

TABLE XV

Individual Corrections for Phonetic Structure

When the syllabic structure of a condition is not expressed in the table, it is understood to be a two-syllable word.

Vowels

$\mathrm{K}$ I. Unacc., first syl.

Exper. $2 A$

Exper. $2 \mathrm{~B}$

$\mathrm{K}$ 2. " final

-.4 III

$-.3379$

$-.0202$

$\mathrm{K}$ 3. First syl., acc., final cons.

$\mathrm{K}$ 4. " " ") cons. doublet

.0006

.0823

$\mathrm{K}$ 5. One syl. word

.1266

$\mathrm{K} 7$ Final, acc.

.1848

$-.1293$

$-.18 \mathrm{I} 7$

$-.0413$

.- II 27

$-.0443$

.0092

.2800

Consonants

$\mathrm{K}$ I. Fina ${ }^{1}$, acc.

Exper. $2 \mathrm{~A}$

$-.2437$

Exper. $2 \mathrm{~B}$

$\mathrm{K}$ 2. " unace.

$\mathrm{K}$ 3. Initial, acc., final cons.

$-.2353$

$\mathrm{K}$ 4. " " long final vowel

$-.2333$

$-.0535$

$\mathrm{K}$ 5. " unace.

$-.0423$

$\mathrm{K}$ 6. One syl. word, initial

$-.0412$

$\mathrm{K}$ 7. " " " final

$-.0235$

$\mathrm{K}$ 8. Initial, acc., 3 syl. word

$\mathrm{K}$ 9. " " cons. doublet in syl.

KIo. Medial, accent following

KII. " " preceding

.0296

.0808

.0940

. I 43

KI2. Initial, acc., long vowel following

$\mathrm{K}_{13}$. " " diphthong following

.1584

.2728

$-.1622$

.0083

$-.1273$

$-.1397$

$-.0870$

$-.0908$

$-.0358$

.1863

$-.1988$ 
of this variable of phonetic structure, the corrections tend to fall into a typological pattern (Tables XV and XVI). The vowel corrections follow essentially the same rank-order in both the magnitude- and the darknessscales, but the consonants do not. The symbolic value of accenting the vowel is heavily in favor of largeness and darkness; the final position of the vowel likewise carries with it a large and dark symbolism. In the consonants, on the other hand, the final position is the weakest for symbolic magnitude and darkness. The structural pattern for the conson-

\section{TABLE XVI}

Typological Corrections ror Phonetic Structure

Experiment $2 \mathrm{~A}$ (Large vs. Small)

The scale-value of a typological correction is the mean of its individual corrections (Table $\mathrm{XV})$. The individual conditions making up a type are given in parentheses.

\begin{tabular}{|c|c|}
\hline \multicolumn{2}{|l|}{ Vowels } \\
\hline $\mathrm{KI}\left(\mathrm{K}_{1}, \mathrm{~K}_{2}\right)$ Unaccented & -.3653 \\
\hline $\mathrm{KII}\left(\mathrm{K}_{3}, \mathrm{~K}_{4}, \mathrm{~K}_{5}\right)$ First syl., acc. & .0256 \\
\hline KIII (K6) One syl. word & .1266 \\
\hline $\mathrm{KIV}\left(\mathrm{K}_{7}\right)$ Fin?l, acc. & .1848 \\
\hline \multicolumn{2}{|l|}{ Consonants } \\
\hline $\mathrm{KI}\left(\mathrm{K}_{1}, \mathrm{~K}_{2}\right)$ Final & -.2403 \\
\hline $\mathrm{KII}\left(\mathrm{K}_{3}, \mathrm{~K}_{4}, \mathrm{~K}_{5}\right)$ Initial unemphatic & $-.101 \mathrm{II}$ \\
\hline $\mathrm{KIII}\left(\mathrm{K} 6, \mathrm{~K}_{7}\right)$ One syl. word & -.0305 \\
\hline $\mathrm{KIV}\left(\mathrm{K} 8, \mathrm{~K}_{9}\right)$ Initial neutral & .0499 \\
\hline $\mathrm{KV}\left(\mathrm{K}_{\mathrm{IO}}, \mathrm{K}_{\mathrm{II}}\right)$ Medial & .1047 \\
\hline $\mathrm{KVI}\left(\mathrm{K}_{\mathrm{I}_{2}}, \mathrm{~K}_{13}\right)$ Initial emphatic & .2155 \\
\hline
\end{tabular}

ants of magnitude-symbolism shows three types of initial position. Psychologically considered, these might be termed: (1) initial unemphatic, when the syllable containing the consonant is unaccented, or when the word ends in a consonant or a long vowel-conditions which might be interpreted as emphasizing some other part of the word than the initial syllable; (2) initial neutral, when the syllable is closed by a consonantal doublet, or when it is part of a three-syllable word; (3) initial emphatic, when the syllable containing the consonant is emphasized by having a long vowel or a diphthong. The medial position is symbolically larger than the initial neutral, but smaller than the initial emphatic.

Phonetic symbolism and English words. The data amassed for the magnitude-values of vowels, consonants, and phonetic structure were employed to determine whether meaningful English words reflected this type of phonetic symbolism. For this purpose a group of words were gathered from Roget's Thesaurus; all the words under the rubrics, Greatness, Smallness, Size, and Littleness were listed (Nos. 31, 32, 192, 193), and the repetitions, derivatives, and phrases were struck out. The resulting list, 
containing almost five hundred words, included many terms which did not seem to belong clearly to the categories of denotative largeness and smallness. The list was then divided into the two denotative classes and given to 11 judges, who were asked to check the words that, in their

\section{TABLE XVII}

Magnitude-Scale Values under Conditions op Phonetic Structure In accord with the procedure of arranging scale-sequence throughout this paper, the stim. ulus with the lowest scale-value is taken as the origin. The consonant-responses of Group 3 ,

Exper. I, have been grafted on the consonantal magnitude scale of Exper. $2 \mathrm{~A}$.

\begin{tabular}{lcccc} 
& \multicolumn{5}{c}{ Vowels } \\
& KI & KII & KIII & KIV \\
$i$. & .0000 & .3909 & .4919 & .5501 \\
$i$. & .2687 & .6596 & .7606 & .8188 \\
$e i$ & 1.0370 & 1.4279 & 1.5289 & 1.5871 \\
$a i$ & 1.1029 & 1.4938 & 1.5948 & 1.6530 \\
$\ddot{a}$. & 1.1045 & 1.4954 & 1.5964 & 1.6546 \\
$y u$. & 1.2521 & 1.6430 & 1.7440 & 1.8022 \\
$u^{\circ}$ & 1.4061 & 1.7970 & 1.8980 & 1.9562 \\
$a$. & 1.6544 & 2.0453 & 2.1463 & 2.2045 \\
$\jmath^{\circ}$ & 1.7047 & 2.0956 & 2.1966 & 2.2548
\end{tabular}

\begin{tabular}{|c|c|c|c|c|c|c|}
\hline & & & & & & \\
\hline & $\mathrm{KI}$ & KII & KIII & KIV & KV & KVI \\
\hline$t$ & .0000 & .1392 & .2098 & .2902 & .3450 & .4558 \\
\hline$c$ & .3215 & .4607 & $.53 \mathrm{I} 3$ & .6 II 7 & .6665 & .7773 \\
\hline$p$ & .3253 & .4645 & $.535 \mathrm{I}$ & .6155 & .6703 & .78 I I \\
\hline$n$ & .3507 & .4899 & .5605 & .6409 & .6957 & .8065 \\
\hline d & .3808 & .5200 & .5906 & .6710 & .7258 & .8366 \\
\hline$f$ & .3819 & .5211 & .5917 & .6721 & .7269 & .8377 \\
\hline$s$ & .4053 & .5445 & $.615 \mathrm{I}$ & .6955 & .7503 & .86 I I \\
\hline$h$ & .5213 & .6605 & $.73 \mathrm{II}$ & .8 II 5 & .8663 & .977 I \\
\hline$k$ & .5496 & .6888 & .7594 & .8398 & .8946 & I. .0054 \\
\hline$t c$ & .5619 & .7011 & .7717 & $.852 \mathrm{I}$ & .9069 & I.OI 77 \\
\hline$\theta$ & .6222 & .7614 & .8320 & .9124 & .9672 & I. 0780 \\
\hline$b$ & .7203 & .8595 & $.930 I$ & I.0105 & I. 0653 & I. $176 \mathrm{I}$ \\
\hline$l$ & .7750 & .9142 & .9848 & 1.0652 & I. I 200 & I. 2308 \\
\hline$v$ & .8769 & I.0I6I & I. 0867 & I. I67I & I. 2219 & I. 3327 \\
\hline$g$ & .9154 & I. .0546 & I. 1252 & I. 2056 & I. 2604 & I. 3712 \\
\hline$j$ & .9296 & I. 0688 & I. I 394 & I. 2198 & I. 2746 & I. 3854 \\
\hline$m$ & .9607 & I. 0999 & I. 1705 & I. 2509 & I. 3057 & I. 4165 \\
\hline$\delta$ & I. 0606 & I . I 998 & I. 2704 & I. 3508 & I. 4056 & I. $5 \mathrm{I}_{4}$ \\
\hline$d j$ & I. 1276 & I. 2668 & I. 3374 & I. 4178 & I. 4726 & I. 5834 \\
\hline$r$ & I. 1615 & I. 3007 & I. 37 I 3 & I. $45 \mathrm{I} 7$ & I. 5065 & I. 6173 \\
\hline$z$ & I. 2255 & I. 3647 & I. 4353 & I. 5 I 57 & I. 5705 & I. $68 \mathrm{I} 3$ \\
\hline
\end{tabular}

opinion, did not conform in meaning to their classifications. The final list, taken from a majority vote of the judges, is printed in Tables XVIII and XIX.

A frequency table was made for the distribution of phonetic sounds in each of these meaningful categories; the values used were those of Table XVII, which includes the symbolic magnitude-values for vowels and for 
consonants under the various conditions of phonetic structure. ${ }^{7}$ This gave two independent approaches to the determination of symbolic magnitude in English words denoting largeness and smallness. It was necessary to construct a third frequency-table for the distribution of short vowels; the

TABLE XVIII

\begin{tabular}{|c|c|c|c|c|}
\hline & & RDS DENOTIN & LLNESS & \\
\hline abate & epitome & melt & portable & spare \\
\hline abridge & evanescent & mere & powder & spark \\
\hline animalcule & & microbe & puny & speck \\
\hline atom & faint & microcosm & puppet & spice \\
\hline attenuate & few & midge & & splinter \\
\hline & flitter & miniature & rag & sprinkling \\
\hline barely & fly & minikin & rare & squat \\
\hline bit & fraction & $\operatorname{minim}$ & rather & stunted \\
\hline bubble & fragment & minimum & reduce & subside \\
\hline button & & minnow & rudiment & subtract \\
\hline & gleam & minor & runt & sup \\
\hline chip & globule & minute & & \\
\hline chit & gnat & mite & scant & $\operatorname{tag}$ \\
\hline close & grain & mitigate & scarce & tatter \\
\hline contract & grub & modest & scrag & tenuous \\
\hline corpuscle & & modicum & scrap & tender \\
\hline crumb & hardly & molecule & scrubby & thin \\
\hline crumble & inch & monad & scruple & tincture \\
\hline decimate & infinitesimal & mote & seldom & $\begin{array}{l}\text { tinge } \\
\text { tiny }\end{array}$ \\
\hline decline & iota & mouse & shade & tit \\
\hline decrease & insect & & shadow & tittle \\
\hline depreciate & & narrow & shaving & tomtit \\
\hline descend & jot & near & sheer & touch \\
\hline $\begin{array}{l}\text { detail } \\
\text { deteriorate }\end{array}$ & just & nutshell & $\begin{array}{l}\text { shiver } \\
\text { short }\end{array}$ & trifle \\
\hline diminish & languish & only & shred & urchin \\
\hline diminutive & least & & shrimp & \\
\hline discount & less & paltry & shrunk & vanish \\
\hline dole & light & paring & simple & \\
\hline doll & Liliputian & part & $\operatorname{sip}$ & wane \\
\hline dot & limited & passable & slender & waste \\
\hline driblet & little & patch & slight & weak \\
\hline drop & look & paucity & slip & wear \\
\hline dumpy & low & pebble & sliver & weazen \\
\hline warf & & petty & smack & wee \\
\hline & maggot & pigmy & small & whit \\
\hline & mannikin & pigwidgeon & snack & worm \\
\hline & meagre & pin & snatch & wretched \\
\hline & mean & pocket & snip & \\
\hline & mediocre & point & sop & \\
\hline
\end{tabular}

values used here were those of Experiment 1; but the variable of phonetic structure was not introduced, this variable having been computed from a

${ }^{7}$ The simplified set of typological conditions (Table XVI) was used in order to avoid unnecessary detail. The consonant doublets, $g l, g r$, and $b r$, were not included in the table of frequency-values because their position on the magnitudescale indicated that they did not behave as consonantal units. 


\section{TABLE XIX}

Words Denoting Largeness

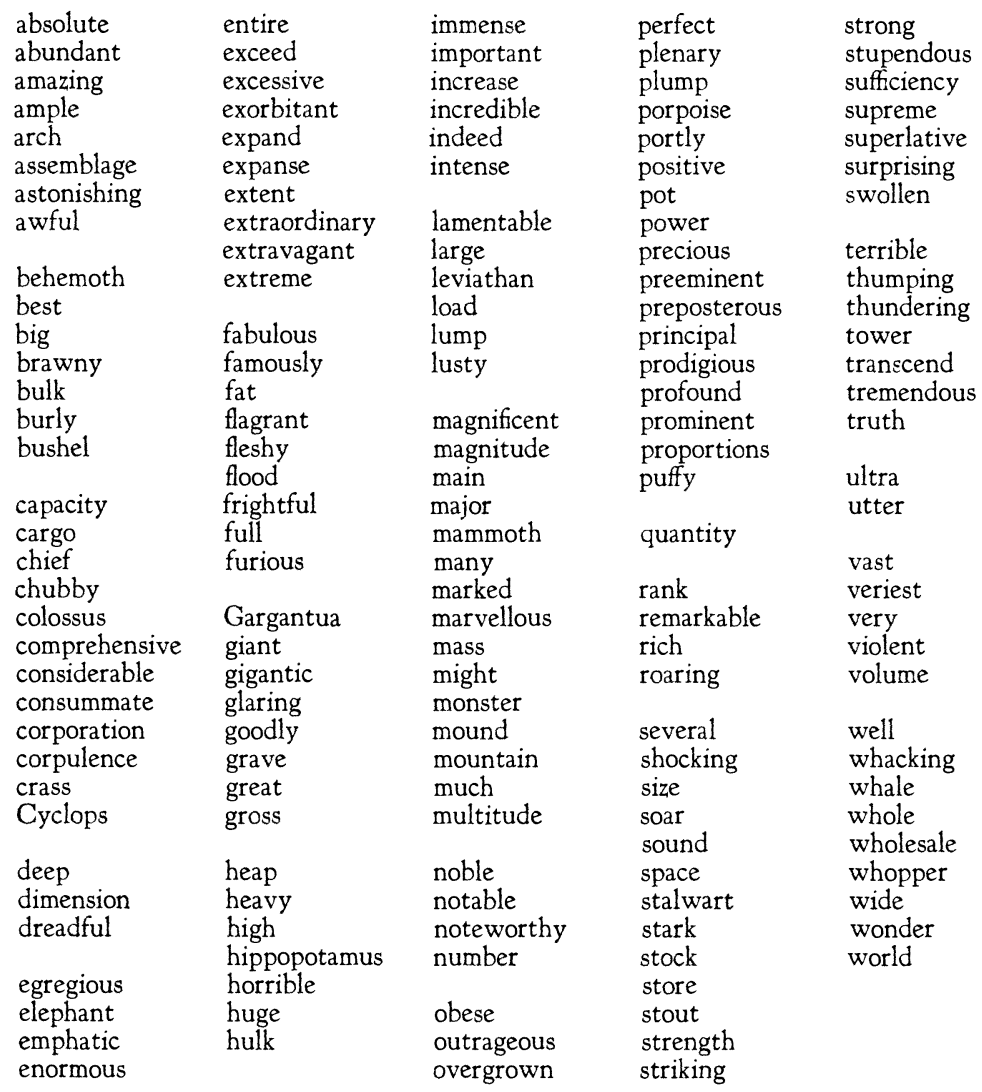

different experiment. The three indexes $(\mathrm{Sf} / \mathrm{f}$, in which $\mathrm{S}=$ the magnitude-value of a phonetic sound on the symbolic scale, and $f=$ the frequency of a phonetic sound in English words) give the average symbolic magnitude of (1) long vowels and diphthongs, (2) consonants, and (3) short vowels. The values of the three indexes are as follows:

$\begin{array}{cc}\begin{array}{c}\text { Words Denoting } \\ \text { Largeness }\end{array} & \begin{array}{c}\text { Words Denoting } \\ \text { Smallness }\end{array} \\ 0.9832 & 0.9162 \\ 0.8476 & 0.8024 \\ 1.3711 & 1.4072\end{array}$
(1) Long vowels and diphthongs
0.9832
0.8024
(2) Consonants
1.3711
1.4072
(3) Short vowels

From this table it must be admitted that the phonetic content of English words takes practically no account of magnitude-symbolism. The large/ 
small ratio of the three indexes is respectively 1.08, 1.06, and .97. It may be argued that English words do show, perhaps, a very slight regard for symbolic value, since the first two indexes are more reliable in taking account of the variable of phonetic structure; but this tendency is so minute as to be negligible. The actual distribution of sounds in the two denotative categories is fairly random, as far as phonetic symbolism is concerned.

These investigations lead us to several conclusions, which may be summed up as follows:

(1) Phonetic elements tend to be rigidly patterned on a non-linguistic symbolic scale. This rigidity of subjective patterning is evinced by the fairly consistent agreement between the three groups of Experiment 1 in respect to the sequence of phonetic stimuli on a symbolic scale as well as to the discriminal distances between them. The suggestions given by the apparent regularity of the discrepancies and by the consistent relations of objectively phonetic factors point to the same conclusion.

(2) The factor of age, as far as this investigation has gone, has little effect on the subjective scale, the slight variations in patterning being mere differences in the degree of consistency and of discriminal clarity. The child of nine years shows the same plan in his symbolic judgments as the adult.

(3) The basis of phonetic symbolism is fundamentally objective. The symbolic scale is constellated in accordance with such mechanical factors as position of articulation, acoustic resonance-frequency, size of oral cavity, vocalic length, consonantal voicing, and phonetic structure.

(4) Diverse types of phonetic patterns are formed by unlike symbolisms. This divergence of patterning is occasioned by a variety of objective factors entering into the symbolic judgments. The sequences of the tongueposition in articulation and of consonantal voicing appear to be basic factors in the patterns of magnitude- and darkness-symbolisms; but such factors as vocalic length and the size of the oral cavity are relevant only for judgments of magnitude.

(5) These symbolic judgments are not produced by linguistic associations. The investigation of the denotative categories of largeness and smallness in English showed practically no correlation between the meaningful and the symbolic distribution of speech sounds. The rigidity of the subjective scale would in itself preclude any such chance factor as linguistic association. The underlying objective rationale of the symbolic pattern would further tend to deny such an assumption, for it could hardly be maintained that the distribution of phonetic sounds in meaningful English words follows a mechanical and objective schema. 